\title{
La política de descentralización: una revisión crítica*
}

\author{
Ma. Concepción Martínez Omaña
}

\section{Introducción}

La temática de la descentralización del Estado, así como el reforzamiento y el nuevo papel de los gobiernos municipales ha cobrado importancia en las últimas dos décadas, tanto en el medio académico como en el político.

México no ha sido ajeno a los procesos descentralizadores formulados e instrumentados primero en Europa y posteriormente en América Latina. Esta situación ha conducido a la incorporación de estos temas como problema de investigación, de discusión teórico-metodológica, de hipótesis, resultados y perspectivas distintas.

El objetivo del presente trabajo es realizar una revisión crítica de algunas de las principales líneas de debate abordadas por algunos autores de las políticas de descentralización y gestión local, tanto en Europa y América Latina como en México. Para ello se estudian algunos aspectos relacionados con dichos procesos y que tienen relación con algunos más: la centralización, la crisis económica, la democratización, el poder local y la participación ciudadana.

En la primera parte se analizan las proposiciones teóricas más importantes en Europa y en América Latina. En la segunda, se revisan algunas de las interpretaciones del proceso de descentralización en México destacando la crisis esconómica, la democracia, la centralización y el gobierno local. Por último, se plantean algunas ideas preliminares sobre la política de descentralización del gobierno mexicano.

\section{Proposiciones teóricas}

La descentralización, según algunos estudios basados en la realidad europea y latinoamericana, ha sido una respuesta a la centralización, resultado de un proceso histórico que provocó, entre otras cosas, la formación de los Estados nacionales.

Así, estos autores sostienen que para comprender el proceso de descentralización es importante no dejar de lado las causas, las características y las consecuencias de la centralización del Estado, donde la crisis del sistema capitalista juega un papel determinante. ${ }^{1}$

* Una versión de este trabajo fue presentada en el seminario Descentralización y cuestión urbana de la Maestría en Estudios Regionales del Instituto Dr. José Ma. Luis Mora, coordinado por la doctora Alicia Ziccardi.

1 Véase Jordi Borja, "La descentralización: una cuestión de método", en Revista Mexicana de Sociologia, núm. 4, 1984; Susana Peñalva, La descentralización del Estado en un contexto de crisis, CEUR, Buenos Aires, 1988; Nuno Portas, "El gobierno 
Jordi Borja ha sido uno de los autores que más ha profundizado al respecto. Éste analiza el proceso de descentralización como producto de la acentuación de la crisis económica, la cual pone en tela de juicio la centralización del Estado.

El desarrollo del Estado moderno ha seguido. . . pautas centralizadoras; la concentración de los recursos financieros de los niveles centrales del Estado. . ., la tendencia del Estado a actuar mediante órganos periféricos descentralizados o autónomos... y el progresivo vaciado de competencias de éstos en beneficio del Estado, son algunos aspectos de la centralización político-administrativa que caracteriza al siglo $\mathrm{xx}^{2}$

La crisis del sistema capitalista, resultado del agotamiento del patrón de acumulación se reflejó, entre otras cosas, en la necesidad de reestructurar y crear nuevos mecanismos que permitieran al capital obtener mayor cobertura para seguir desarrollando sus niveles de ganancia; de ahí que la centralización de las funciones administrativas, económicas y políticas tengan que sufrir modificaciones relevantes que conlleven a nuevas formas de organización de las sociedades modernas.

En este contexto de crisis se acentúan las propuestas descentralizadoras, tanto en el ámbito académico como en el político.

Borja plantea que "la descentralización significa abrir cauces para el desarrollo de la iniciativa y de la organización de la sociedad civil, para facilitar la actividad autónoma de nuevos actores económicos y sociales y para avanzar a un nuevo tipo de economía social y de derecho que se sitúen entre lo público y lo privado..."3

Otra línea de análisis es aquella que vincula la descentralización con el proceso de democratización política gestado en las últimas dos décadas. Al respecto la propuesta de Alejandro Rofman sostiene que la descentralización y la democracia son conceptos indisolublemente unidos:

Descentralizar es ampliar la base del sistema de toma de decisiones acerca de la función pública a los habitantes, incrementar la influencia de Ios residentes en provincia. . Descentralizar será entonces adoptar el proceso necesario para una redistribución del poder con auténtica participación popular. ${ }^{4}$

Borja también comparte esta opinión y sostiene que la descentralización como proceso democratizador debe suponer:

. . una política deliberante y representativa dotada de autonomía con el ejercicio de sus competencias, de carácter global; donde se transfieran competencias de carácter decisorio con capacidad de coacción y disponibilidad de recursos propios. . .; también supone una tendencia a asumir la gestión por delegación y de los servicios que se prestan y . . . además implica un desarrollo de nuevos mecanismos de participación política. ${ }^{5}$

del territorio en la experiencia europea", en Hall y otros, Metrópolis, territorio y crisis, ed. Asamblea de Madrid, Madrid, 1985; Alejandro Rofman, Descentralización y democracia, F. Friedrich Ebert, Buenos Aires, 1986.

2 Jordi Borja, "Descentralización...", op. cit.

3 lbid.

4 Alejandro Rofman, Descentralización y. ., op. cit., p. 12.

5 Jordi Borja, "Descentralización. ..", op. cit., p. 9. 
Para Susana Peñalva no necesariamente existe una relación lineal entre descentralización y democracia. Esta autora identifica dos elementos de la interrelación Estado-sociedad, involucrados cuando se hace referencia a la descentralización y a la democracia a nivel nacional: el primero se refiere a la organización territorial del Estado en diferentes niveles de gobierno, desde un punto de vista estructural y que alude a la dimensión de la descentralización entendida como un proceso político administrativo y el segundo indica las formas de representación política y de participación social directamente vinculadas a la democratización del Estado.

Hilda Herzer y Lordello de Mello, a partir de sus estudios sobre América Latina, relacionan la temática del proceso descentralizador con la discusión del poder local, es decir, con el papel que cumple el gobierno local en dicho proceso. Sostienen que la reforma municipal y la redefinición de los gobiernos responden a una política de descentralización y modernización del Estado. Lordello de Mello propone una nueva interpretación de la modernización de los gobiernos locales:

Modernizar consiste en cuestionar sistemáticamente la posición y el papel de los gobiernos locales. . . en el sistema gubernamental; la eficiencia y la eficacia en la prestación de los servicios públicos y la equidad y la justicia con que dichos servicios son distribuidos a los distintos grupos sociales. . . Implica además, cuestionar el proceso de toma de decisionẹs, de manera de involucrar la participación ciudadana en el establecimiento de prioridades y en la distribución de los beneficios sociales de la acción gubernamental. ${ }^{6}$

Así, la modernización de los gobiernos locales se define como la permanente adecuación de su estructura básica, de sus poderes, de sus funciones, de su organización interna y de sus procedimientos operativos a las necesidadés de la comunidad que sirven y al cumplimiento de un papel consecuente en el proceso de desarrollo nacional.

Según Manuel Castells y Jordi Borja, los principales problemas que debe abordar la gestión municipal son la disponibilidad de recursos económicos, la modernización de la administración, la democratización de las instituciones, la descentralización municipal y la participación ciudadana. De éstos es importante destacar el que se refiere al proceso de descentralización de la gestión municipal en las grandes ciudades, el cual consiste: "en la transferencia de competencias, recursos y personal, a nivel de distritos, zonas, barrios, de forma que aumente su eficacia y su flexibilidad mediante un conocimiento más directo de los problemas más concretos de cada barrio y una compenetración más íntima con la población".?

Las políticas de descentralización y modernización en América Latina han tenido significados y contenidos diversos en los países del área, ya se trate de países con regímenes democráticos o autoritarios.

6 D. Lordello de Mello, "Modernización de los gobiernos locales en América Latina", Revista Interamericana de Planificación, México, vol. xvil, núm. 66, junio de 1983.

7 M. Castells y otros, "Urbanización y democracia en América Latina", en J. Borja (coord.), Manual de gestión municipal democrática, Instituto de Estudios de Administración Local, Madrid-Barcelona, 1987, p. 55. 
En la mayoría de las naciones supuso una redefinición del papel y del rol de los gobiernos locales y, mediante un proceso de reforma municipal, aspirar a una mayor eficacia: en otros, una adecuación del Estado a las nuevas condiciones sociales y políticas con el propósito de garantizar la vigencia de las estructuras de dominación.

Por ejemplo en el caso chileno, dentro del marco de un proceso de modernización del Estado, se concilió el liberalismo económico y el autoritarismo político mediante las "siete modernizaciones sociales: el plan laboral, la reforma previsional, la directiva educacional, la reforma de la salud, la modernización judicial, el reordenamiento de la agricultura y la reforma administrativa".

Una línea del proceso de reforma municipal llevado a cabo por el régimen chileno fue la drástica congelación y reestructuración municipal que determinó la sumisión de esta institución al ejecutivo:

. . . una nueva estructura. . (decreto 573 denominado "estatuto de Gobierno y Administración Interiores del Estado"). . . por la cual la administración y el gobierno del país se asimilan a una jerarquía regionalizada con fines específicos de descentralización. . Se oficializa así una división del país en regiones, provincias y comunas (y se crean) áreas metropolitanas especiales. ${ }^{8}$

Todo esto con el fin de dcspolitizar el sistema municipal y limitar la autonomía local.

Kusnetsoff destaca entre uno de los rasgos del proceso de descentralización en Chile el traspaso masivo de la administración de los establecimientos públicos educacionales (primario y secundario) a los municipios de todo el país y los de carácter técnico y profesional en forma directa a entidades privadas. Reforma municipal que expresa la "desmovilización del profesorado, la mentalidad orientada hacia el individualismo y la competencia, la omisión de la crítica y un control ideológico". 9

Otro ejemplo que puede ilustrar la descentralización en países democráticos es el nicaragüense. En Nicaragua la reforma municipal pretendía readecuar la política de descentralización en las dimensiones de poder y participación popular.

El gobierno de Reconstrucción Nacional desde su llegada al poder distinguió entre los temas prioritarios: una firme voluntad de desarrollo regional y descentralización, en un marco más igualitario, que tendiera a revertir el proceso histórico de concentración de la población e inversiones en la zona del Pacífico y, en especial, de la capital.

Para lo cual el modelo político del nuevo régimen se propuso un cambio de la sociedad a fondo mediante:

. . una transformación popular, demográfica, gradual y nicaragüense, a un ritmo de marcha coherente, que mejore el bienestar social a los desposeídos... En términos regionales, esta transformación [propuso] una serie de medidas descentralizadoras paralelamente a una mayor interven-

${ }^{8}$ Fernando Kusnetsoff, "Democratización del Estado, gobiernos locales y cambio social. Experiencias comparativas de Chile y Nicaragua", Revista Mexicana de Sociología, IISUNAM, México, año xlv, núm. 1, enero-marzo de 1983, p. 301.

9 Fernando Kusnetsoff, op. cit., p. 205. 
ción del Estado... mediante: a) un proceso de centralización interna [para] fortalecer la dirección unificada de la economía, para impulsar el proceso de centralización de excedentes. . [ [y] b) un proceso de descentralización, expresado en el fortalecimiento de la capacidad operativa de los departamentos y gobiernos locales para realizar tareas en el campo social, en el de la producción y en el de abastecimiento. ${ }^{10}$

Por otra parte, Francisco Velázquez y Fernando Viviescas rescatan el municipio como espacio de reflexión y de conocimiento del significado de la vida ciudadana, en tanto bases de la reformulación de la participación social mediante la confirmación de un poder local, que se apoye en el conocimiento de las condiciones concretas de existencia de cada municipio y de su relación con el ente nacional.

Viviescas propone el espacio urbano colectivo como centro de la reformulación de políticas que pugnen por el espacio libre, es decir, mayor ámbito público y el fortalecimiento de las demandas en términos de la calidad de esa especialidad: la creación, la ampliación y la cualificación de las posibilidades de disfrute de ese espacio para la colectividad como "manera de identificar al ciudadano con su ciudad y darle presencia al municipio como realidad institucional"."1

Algunos autores latinoamericanos analizan la relación descentralización-cuestión urbana, tomando en cuenta los efectos de la crisis sobre el espacio urbano. Peñalva sugiere que la emergencia creciente de demandas insatisfechas para la población, las reivindicaciones y la defensa de los niveles de consumo son algunos elementos más importantes de la relevancia del espacio social considerado un ámbito privilegiado donde se manifiesta la crisis y la especificidad de sus efectos en lo "urbano" en las sociedades latinoamericanas.

Dos temas en relación con la crisis y la cuestión urbana son planteados por esta autora: uno es el que articula la relación entre espacio urbano, sociedad y Estado en América Latina. Siguiendo la propuesta de Castells, señala que esta relación depende de la forma en que las sociedades organicen la economía, y las relaciones sociales por medio de la trama de las relaciones internacionales. Así, la problemática urbana tiene un sentido muy diferente en las sociedades dependientes en comparación con las centrales; el segundo es la preocupación en torno a los efectos urbanos de la crisis. En este sentido, destaca la intervención desde el Estado o desde la sociedad, que traducidas en propuestas alternativas sobre las formas espaciales, se convierten en gestión del territorio y en el papel de los agentes sociales mientras sean válidos para enfrentar la crisis. La consecuencia de este problema ha sido, según Peñalva, que se ponga especial atención en la problemática local, formulándose también planteamientos de descentralización junto con estrategias alternativas de política urbana.

Otro aspecto que destaca la autora es que la política de descentralización tropieza con obstáculos de índole burocrático y económico, lo cual obliga a orientar el análisis de esta política a nivel sectorial y su viabilidad en determinados territorios.

10 F. Kusnetsoff, op. cit., p. 205.

11 Fernando Viviescas, "Identidad municipal y cultura urbana", Revista Mexicana de Sociología, ilsunam, México, año xivili, núm. 4, 1986, p. 59. 


\section{Interpretaciones en torno a la descentralización en México}

En México, al igual que en América Latina, la descentralización cobró importancia tanto en el ámbito académico como en el político a partir de la década de los ochenta. Ese proceso también ha originado diversas interpretaciones, según la idea de quienes la han analizado e instrumentado.

Hay quienes sostienen que la política estatal de descentralización se ha orientado a trasladar a niveles inferiores de gobierno la solución de la crisis y de los problemas existentes; con ello el Estado pretende disminuir las presiones sociales en el centro de la dominación política y económica. Para otros autores, esa política es una respuesta a la crisis económica y, otros preocupados por el sistema político mexicano, la relacionan con algunos aspectos de la reforma política, de los procesos electorales y de las organizaciones políticas en el plano local. Éstos consideran que la descentralización contribuye a la ampliación del espectro partidario y, en definitiva, a la democratización del sistema político. ${ }^{12}$

También es posible diferenciar a quienes conciben ese proceso como una combinación de ambos niveles. Alicia Ziccardi y Carlos Martínez Assad plantean que para comprender el proceso de descentralización se necesita enmarcarlo en los efectos negativas que tiene la crisis económica sobre la sociedad y las crecientes expectativas de la ciudadanía por profundizar la democratización. Ambos autores sostienen que:

El proceso de descentralización está directamente relacionado con aspectos centrales de la política económica adoptada por los últimos gobiernos en el contexto de la crisis. Igualmente, la efervescencia de movimientos sociales y políticos permitió avances de la oposición partidaria ocupando posiciones en distintas esferas del aparato estatal. Lo cual, en la práctica, se enfrentó en las diferentes disputas protagonizadas en las localidades del territorio nacional. ${ }^{13}$

Señalan que a principios de los ochenta, el país se entrentó a una de las crisis más severas de su historia, la cual se reflejaba en el incremento de las tasas de desempleo y subempleo, en la caída del precio del petróleo y en el aumento de las tasas de interés nacionales e internacionales. En 1985, se agregaron los efectos del terremoto que asoló a la ciudad de México, lo cual agudizó aún más las consecuencias de Ia crisis. En su conjunto, estos factores provocaron una serie de presiones que originaron la disminución del gasto público y la política del adelgazamiento del Estado, por la vía de la venta de paraestatales y el retiro de éste de importantes ramas productivas.

En 1983, Miguel de la Madrid inicia un proceso de reordenación económica con el fin de recuperar la capacidad de crecimiento, elevar el nivel de desarrollo del país y para atender los efectos más graves de

12 Véase S. Peñalva, op. cit.; A. Ziccardi y C. Martínez Assad. La descentralización de las políticas públicas en México (mimeo.); A. Monjardin L., Los ayuntamientos. Una utopia viable; A. Moreno Toscano, "México modelo a desarmar", en El desafio mexicano, Océano, México, 1982.

13 A. Ziccardi y C. Martínez Assad, "La descentralización de las políticas públicas en México", ilsunam, México, 1988, p. 6. 
la crisis: "La inflación, el déficit fiscal, el desbalance del comercio internacional, el control salarial, la diversificación e incremento de las exportaciones fueron los componentes claves de la nueva política económica". ${ }^{14}$

De la crisis y de la política económica delamadridista surgiría también un nuevo modelo de organización estatal, un nuevo Estado, otras formas de participación política, instituciones que pretenden mayor funcionalidad y la maduración de un nuevo orden social.

En este marco, la descentralización se convierte en uno de los instrumentos del Estado mexicano para reorientar la economía y responder a los reclamos sociales que demandan, entre otras cosas, la ampliación de los ámbitos de representación política y democrática. Para Ziccardi y Martínez, el gobierno de Miguel de la Madrid incluyó la descentralización de la vida nacional como parte integrante de las tesis que agrupaban su percepción de los problemas y de las soluciones sociales, económicas y políticas que presentaba la coyuntura. Dicha política se apoyaría en tres líneas generales de acción: fortalecer el federalismo, la vida municipal y fomentar el desarrollo regional.

Según Alejandro Massolo, la política de descentralización pretende una reforma clave dentro de la gestión política del Estado: la planeación del desarrollo en un periodo de aguda y extendida crisis, que se ubica dentro de lo que se ha llamado "el fuego cruzado de las presiones" al que está sometido el centralismo de los Estados latinoamericanos. La autora plantea el origen de esas fuerzas:

Presiones que provienen desde las bases territoriales, comunidades y gobiernos locales, como desde dentro del mismo aparato del Estado central e intentan, además de hacerlo eficiente, racionalizar la operación de su funcionamiento institucional y la utilización de un gasto público más reducido. ${ }^{15}$

Con anterioridad, Alejandra Moreno Toscano había analizado el proceso de descentralización retomando ideas del discurso oficial. Su estudio no parte del problema de la crisis económica sino de la centralización de la vida política y económica del país, la cual ha provocado, entre otros problemas, un crecimiento urbano desmedido, el empobrecimiento del campesino, la macrocefalia de la ciudad de México y el raquitismo municipal. Sostiene, desde una nueva interpretación oficial del pasado, que:

Durante la revolución el centralismo fue el instrumento que favoreció a las grandes transformaciones estructurales (reforma agraria, creación de instituciones financieras, etcétera). Ese mismo mecanismo ha entrado hoy en una etapa de rendimientos negativos. El gobierno federal tiene tal cúmulo de atribuciones que se ha convertido en un obstáculo para el desarrollo del país, ha degenerado en una burocracia lenta, ineficaz, obstaculizadora que impide la democracia y provoca deseconomías. ${ }^{16}$

14 Ibid., p. 27.

15 Alejandra Massolo, "La corriente hacia abajo: descentralización y municipio", en Rerista Mexicana de Ciencias Politicas y Sociales, rcpy sunam, México, año xxxiI, núm. 128, abril-junio de 1987, p. 125.

16 A. Moreno Toscano, op. cit., p. 65. 
Para esta autora, el gobierno mexicano se sobrecargó de funciones y atribuciones, lo que originó su debilitamiento en instancias de gobierno y de poder. El aparato creció y generó intereses particulares, así comr acciones competitivas y contradictorias. Sin embargo, considera que el gobierno no ha sido el único responsable de todas y cada una de las necesidades sentidas por la población, pues formas organizativas comienzan a responder a esta imagen: colonos, maestros, etcétera: "La imagen de enormes masas y un solo individuo interlocutor no asegura necesariamente desarrollos democráticos". Por último, plantea que la descentralización es necesaria y urgente para estructurar de otra manera los mecanismos políticos de participación.

Otra línea de análisis ha privilegiado la relación descentralización-poder local, enfatizando la explicación del municipio como último eslabón de la vinculación Estado-sociedad. Massolo, Ziccardi y Martínez Assad coinciden en señalar que la búsqueda y encuentro del universo municipal se está intensificando por la convergencia entre el aumento de conflictos, la crisis de los poderes locales de tipo tradicional y las luchas políticas manifiestas en las elecciones de los ayuntamientos y por las reformas y adiciones al artículo 115 constitucional, que el Estado mexicano ha promovido en años recientes. Ziccardi y Martínez afirman que:

En los últimos años tanto los administradores como los políticos y los estudiosos reivindican la importancia estratégica del espacio municipal, para unos como un nuevo ensanchamiento del Estado, para otros como un nuevo espacio de la sociedad civil. Todos tendieron a coincidir en la necesidad de incluir al municipio en la discusión sobre la organización política y el futuro del país. ${ }^{7}$

En este sentido, la administración del gobierno de Miguel de la Madrid, apoyándose en los alcances de la reforma política emprendida en el sexenio lopezportillista, lleva a cabo la reforma municipal por medio de la modificación de algunos aspectos del artículo $115 \mathrm{y}$ que se convierten en pieza clave de la descentralización de la vida nacional:

La reformas jurídicas propuestas y aprobadas encerraban cambios sustanciales sobre las funciones, atribuciones y recursos para la gestión local. La reforma pretendía recuperar las preocupaciones jurídicas y sociales que existían en relación con el comportamiento de las entidades que conforman la federación. Dichas modificaciones delimitaban jurídicamente el marco de actuación de estados y municipios en su relación con la comunidad. ${ }^{18}$

Los autores destacan que las reformas introducidas dotaron de capacidad al municipio para asumir el suministro de servicios a la población y del control sobre la apropiación y uso del territorio, así como permitir la participación proporcional de diferentes fuerzas políticas en la composición del ayuntamiento y en las legislaturas 
locales y normar las relaciones entre los estados y la unidad política formada por el municipio. Estos instrumentos jurídicos, políticos y económicos son de importancia para reestructurar las funciones que deben cumplir las instituciones del Estado en el marco de los grandes proyectos nacionales como la descentralización y el impulso a la participación democrática. Massolo sostiene que, dentro del marco donde se replantean los enfoques del problema y la naturaleza de la democracia, se está manifestando un movimiento de descubrimiento y reflexión hacia abajo, es decir, hacia los espacios locales y municipales en cuanto territorios políticos, étnico-culturales, sociales y económicos que deben ser reconocidos y reivindicados por la lucha democrática en el campo popular.

Un ejemplo de esta línea de estudio puede ser el estudio de Adriana López Monjardin sobre el municipio. Esta autora indica que la intensificación de la lucha por los ayuntamientos se debe a una confluencia de fenómenos nacionales que han replanteado la importancia de los municipios:

El énfasis de los programas oficiales sobre la planificación regional y la descentralización administrativa, la reforma política y el debate ideológico intensificado recientemente empieza a modificar el largo olvido en que vivieron los municipios y el desconocimiento de los innumerables conflictos que se generaron en ellos. ${ }^{19}$

López Monjardin considera que los municipios, en tanto espacio de organización territorial e instituciones estatales, constituyen instancias fundamentales de articulación. En ellas se enlaza a la población con sus gobernantes, se cierra el último eslabón que va de la nación a la localidad, se consuma la primacía de lo urbano y se buscan las formas de organización y reproducción de los diversos grupos sociales, antagónicos o no, que comparten un mismo territorio. Massolo hace referencia al gobierno municipal como espacio político institucional en el que se expresa la representación, alianza, confrontación y disputa de los intereses, fuerzas y organizaciones sociales que marcan y configuran el territorio político local, dentro del contexto regional y nacional.

La reforma municipal, según López Monjardin, es expresión de la reforma política, en tanto pretende actualizar la contienda pluripartidista mediante la inclusión de nuevas opciones con un mayor margen para el desarrollo de las actividades y permite reforzar el control corporativo de las masas. Así, el Estado induce la escisión permanente entre la oposición política y las luchas populares reivindicativas, reservando para los organismos oficiales la dirección paralela de ambos planos. Para la autora, la debilidad de esta idea reside en que los municipios, donde los núcleos opositores realizan los combates sociales, se han convertido en posibilidades reales de conquista del poder, luchando en el plano electoral y disputando al Estado la capacidad de movilización.

Martínez Assad, junto con el trabajo de López Monjardin, han dado cuenta de la importancia y la significación de las luchas muni-

19 A. López Monjardin, Los ayuntamientos. Una utopia viable, Siglo XXI Editores, México, 1986. 
cipales en las últimas dos décadas, las cuales expresan en gran medida la búsqueda de dernocracia, enfrentándose a las formas tradicionales de dominación, la exigencia de la ampliación de los derechos ciudadanos, la democratización de las instituciones estatales y el mejoramiento de las condiciones de vida de los habitantes.

Massolo explica que la variedad de demandas y luchas revelan las causas y los procésos sociohistóricos distintos, tales como étnicocampesinos, urbano-populares, obrero-sindicales, político-religiosos con sus propias demandas, objetivos, representaciones y organizaciones dentro del territorio municipal.

\section{A manera de conclusión}

Han sido varios los autores que cuestionan el proceso de descentralización en México desde diferentes puntos de vista.

Primero: algunos autores coinciden en plantear que la descentralización tiene como objetivo acercar el gobierno a la ciudadanía para conocer y resolver los problemas, lo cual lleva a la apertura de nuevos canales de participación social y a la redistribución de recursos y de poder.

Tomando en consideración esta idea sostienen que la descentralización y la reforma municipal son propuestas de acción incorporadas.en proyectos políticos progresistas

Moreno Toscano señala que las ideas rectoras sobre la descentralización tienen un carácter democratizador, pues significa una redistribución de competencias y creciente participación de la comunidad en las decisiones del gobierno, un carácter económico en tanto significa la localización menos concentrada de la actividad económica y la dotación más equilibrada de infraestructura y de servicios a las diferentes zonas del país, un carácter institucional pues introduce cambios de las dependencias gubernamentales y transforma los mecanismos de comunicación interna del sector público, así como las relaciones que se establecen entre la población demandante de servicios municipales y la administración encargada de gestionarlós; un carácter social que requiere de la suma de esfuerzos de la sociedad y el gobierno.

Sin embargo, la descentralización ha estado más orientada hacia la legitimación del discurso político que al terreno de la acción pública. ${ }^{20}$

Segundo: en el discurso oficial la propuesta descentralizadora contiene una serie de imprecisiones. La descentralización aparece como un concepto difuso. Algunos autores coinciden en señalar que se llega a confundir el sistema federal con la creación de estructuras administrativas descentralizadas. Con un mismo término se designan acciones diferentes: la descentralización se emplea indistintamente para referirse a desconcentración, transferencia, delegación; asimismo, hace referencia tanto a las secciones de las dependencias centrales en los estados para facilitar las acciones administrativas como las medidas que buscan revitalizar las unidades políticas para desconcentrar el poder.

20 C. Martínez Assad y A. Ziccardi, "Política y gestión en México", Cuadernos de Investigación, IISUNAM, México, núm. 18, 1987. 
Tercero: uno de los límites de la política de descentralización en México, distinguido por varios autores ha sido el cuestionamiento de las fórmulas homogéneas propuestas por el Estado, que no toman en cuenta los diversos grados de descentralización que se deben plantear en funcićn de las características de los estados y los municipios. Según Massolo, es necesario especificar el cómo, el dónde y el para qué descentralizar. Además dicha política ha sido criticada por ser una propuesta planteada por el centro, es decir, proveniente del gobierno federal, sin la participación de los actores sociales locales.

Cuarto: al parecer, la descentralización de las funciones hacia los municipios no ha significado necesariamente una descentralización real del poder, ni una participación democrática de la población en la toma de decisiones. La dominación del Estado central se mantiene.

Al respecto, Ziccardi y Martínez Assad plantean que para un Estado con graves problemas económicos y sociales en el marco de una grave crisis económica, la descentralización era el medio para disminuir algunos de ellos, los más apremiantes. Una vez que la centralización dejaba de ser el camino para solucionar los problemas se propone la descentralización.

Quinto: otro punto que se ha planteado se refiere al verdadero significado de la reforma municipal. Se cuestiona hasta dónde las propuestas de descentralización han implicado el fortalecimiento de los municipios, si habrán de ser una instancia para administrar los desequilibrios regionales aplicando con mayor rigor las políticas y programas diseñados desde el centro o favorecerán algunas regiones a costa de la creciente marginación de otras.

Sexto: la instrumentación del proceso de descentralización, sobre todo a partir de la evaluación de sus avances, ha presentado una serie de obstáculos. Martínez Assad y Ziccardi han destacado algunos: escasez de recursos de la mayoría de los municipios, resistencia de la burocracia a inaugurar experiencias democráticas de gestión de territorio, rigidez y desarticulación de las instancias e instituciones del gobierno, la existencia de relaciones de poder caciquil, así como la estructura corporativa del partido gobernante, entre los más importantes.

Séptimo: en términos globales la política de descentralización en México se está elaborando. Las ideas expuestas por los autores que hemos revisado son esfuerzos por comprender los alcances y los logros del proceso. El impacto que dicha política ha tenido en los ámbitos estatales y municipales (locales) es una línea de trabajo $\mathrm{e}$ investigación insoslayable para avanzar en el conocimiento de esta problemática. 